\title{
The Role of the Dominant Modes of Precipitation Variability over Eastern Africa in Modulating the Hydrology of Lake Victoria
}

\author{
Kara A. Smith and Fredrick H. M. Semazzi \\ Department of Marine, Earth and Atmospheric Sciences, North Carolina State University, Raleigh, NC 27695, USA \\ Correspondence should be addressed to Kara A. Smith; kasmith5@ncsu.edu
}

Received 18 May 2014; Accepted 4 August 2014; Published 16 September 2014

Academic Editor: Lian Xie

Copyright (C) 2014 K. A. Smith and F. H. M. Semazzi. This is an open access article distributed under the Creative Commons Attribution License, which permits unrestricted use, distribution, and reproduction in any medium, provided the original work is properly cited.

Previous water budget studies over Lake Victoria basin have shown that there is near balance between rainfall and evaporation and that the variability of Lake Victoria levels is determined virtually entirely by changes in rainfall since evaporation is nearly constant. The variability of rainfall over East Africa is dominated by El Niño-Southern Oscillation (ENSO); however, the second and third most dominant rainfall climate modes also account for significant variability across the region. The relationship between ENSO and other significant modes of precipitation variability with Lake Victoria levels is nonlinear. This relationship should be studied to determine which modes need to be accurately modeled in order to accurately model Lake Victoria levels, which are important to the hydroelectric industry in East Africa. The objective of this analysis is to estimate the relative contributions of the dominant modes of annual precipitation variability to the modulation of Lake Victoria levels for the present day (1950-2012). The first mode of annual rainfall variability accounts for most of the variability in Lake Victoria levels, while the effects of the second and third modes are negligible even though these modes are also significant over the region.

\section{Introduction}

Lake Victoria is approximately $67,000 \mathrm{~km}^{2}$ in area but shallow with an average depth of only $40 \mathrm{~m}$. It is territorially administrated by Tanzania, Uganda, and Kenya and is a major source of income in those countries producing \$3-4 billion annually. The lake basin provides fresh water and hydroelectric power for over 30 million people who live in the Lake Victoria basin, as well as supporting agriculture, fisheries, trade, and tourism. The lake is the primary source of the White Nile which flows through Lake Kyoga in Uganda and Lake Albert into Sudan, where it joins with the Blue Nile at Khartoum to form the Nile River, which supports the livelihood of over 300 million people.

The climate of the lake basin is dominated by the bimodal signature of the intertropical convergence zone (ITCZ). It is well known that El Niño-Southern Oscillation (ENSO) and the Indian Ocean Zonal Mode (IOZM) dominate the interannnual climate variability of Eastern Africa $[1,2]$.
Bowden and Semazzi [2] examined the intraseasonal climate variability over the Greater Horn of Africa during the October-December rainy season using empirical orthogonal function (EOF) analysis of pentad data for 1979-2001. The two dominant modes for that season were found to be a mixture of El Niño-Southern Oscillation-Indian Ocean Dipole and a decadal mode. Schreck III and Semazzi [3] found that the second most significant October-December regional precipitation EOF mode was significant over this region. The mode is characterized by decadal variability and a dipole rainfall loading pattern. Indeje et al. [4] analyzed the evolution of ENSO throughout the region and found that relatively wet conditions were observed during the March-May and October-December rainfall seasons of the El Niño years.

The spatial distribution of rainfall over Lake Victoria basin is complex, consisting of a wave-like dry-wet-dry-wet climatological rainfall pattern. This climatic pattern, its variability, and associated atmospheric and marine conditions determine the performance of the primary socioeconomic 
activities across the basin, including agriculture, fisheries, and hydroelectric power generation. The productivity of hydroelectric dams along the Nile River is, to a large extent, determined by the level of Lake Victoria, which is primarily dictated by the rainfall variability over the Lake Victoria basin. Because of this, it is important to determine the modes of variability in precipitation, which dominate the variability in lake levels.

Many studies [5-8] have utilized water balance models of Lake Victoria to close the water balance for the lake as well as to examine the sharp increase in levels from 1961 to 1964 and the decline afterwards. Yin and Nicholson [9] used observed lake levels and a water balance model to estimate rainfall over the lake basin. More recently, studies have been done in order to attribute the recent decrease in Lake Victoria to droughts and release from the hydroelectric dams which control the lake outflow [10-12].

While previous studies in this region have examined either the dominant modes of climate variability or the impact of total rainfall on Lake Victoria levels, the primary objective of this study is to estimate the relative contributions of the dominant modes of annual precipitation variability to the modulation of Lake Victoria levels. The relationship between precipitation over Lake Victoria basin and lake levels is nonlinear. This relationship should be studied to determine which modes need to be accurately modeled in order to accurately model Lake Victoria levels, which are important to the hydroelectric industry in East Africa.

\section{Methods}

The primary method of investigation is a water balance model in combination with application of EOF analysis of the regional Eastern Africa rainfall using the University of East Anglia Climate Research Unit (CRU) version 3.21 [13] over a region covering $10.67^{\circ} \mathrm{S}-4.25^{\circ} \mathrm{N}$ and $29.98^{\circ} \mathrm{E}-41.9^{\circ} \mathrm{E}$. The water balance model employs rainfall at six discrete locations around the lake to construct Lake Victoria levels. We adopt the EOF approach to isolate the contribution of individual significant EOF modes and to reconstruct the lake levels based on the water balance model. The results are compared with Lake Victoria levels constructed using the total rainfall. The time series from the significant seasonal modes are correlated with NOAA Extended Reconstructed Sea Surface Temperature (ERSST) v3b global sea surface temperatures (SSTs) to investigate the physical mechanisms responsible for each mode.

2.1. Empirical Orthogonal Function (EOF) Analysis. Empirical orthogonal function (EOF) analysis [14] was performed on precipitation in Eastern Africa in order to examine the effect of different modes of precipitation variability on rainfall over the region. We test for significance of the modes using Kendall's [15] criterion for distinctly separated EOFs, for sample size $N$, that the sampling error associated with a given eigenvalue must be smaller than its spacing from the neighboring eigenvalue. We then relate the spatial patterns to known physical properties, such as ENSO and IOZM. EOF analysis is performed on annual precipitation since annual precipitation is the input in the water balance model used in this study. Seasonal modes of variability are also found and compared to the significant annual modes to determine their physical properties.

Reconstruction of variables utilizing a systematic inclusion of a subset of eigenmodes which account for most of the data variability has been utilized to filter out statistical noise by reconstructing the data using a reduced number of significant EOF modes. We reconstructed rainfall over the lake basin with only one significant model of variability at a time to examine the contributions of the individual modes to Lake Victoria levels. Since the water balance model used in this study takes in annual precipitation, precipitation is only reconstructed for the annual modes of variability. Our data reconstruction procedure is similar to the approach used in Weickmann and Chervin [16] and Semazzi et al. [17]. Since the EOF analysis was calculated based on the normalized correlation matrix, we first denormalize the data by multiplying the data by the standard deviation for each grid point and then adding the resulting anomalies to the mean. The reconstruction was then performed using the equation

$$
q_{j}(\lambda, \phi)=\bar{q}(\lambda, \phi)+\sum^{M} g_{i j} e_{i}(\lambda, \phi) s(\lambda, \phi)
$$

where $\bar{q}(\lambda, \phi)$ is the time mean vector, $M$ is the number of the selected set of EOFs used in the reconstruction, $g_{i j}$ is the principal component at time $j$ for the eigenvector, $i, e_{i}(\lambda, \phi)$ is the $i$ th eigenvector, and $s_{i}(\lambda, \phi)$ is the standard deviation. The annual mean for the reconstructed data is identical to the corresponding mean for the reconstructed data, independent of the number of modes used in the reconstruction of the percentage of variability covered by the modes.

2.2. Water Balance Model. Tate et al. [8] developed a water balance model based on those used in previous studies [5$7,18]$ to estimate the level of Lake Victoria at the end of a given year $\left(L_{n}\right)$ by calculating the change in the lake level during the year $(\Delta L)$ and adding it to the projected level for the previous year $\left(L_{n-1 \text { (estimated) }}\right)$.

The change in lake level is calculated as follows:

$$
\Delta L_{n}=\left[P-E+\frac{Q_{\text {in }}-Q_{\text {out }}}{A}\right]_{n},
$$

where $P$ and $E$ are precipitation and evaporation over the lake, respectively, $Q_{\text {in }}$ is inflow into the lake from tributaries, $Q_{\text {out }}$ is outflow from the dams at Jinja, and $A$ is the surface area of Lake Victoria. Evaporation is assumed constant at $1595 \mathrm{~mm} \mathrm{yr}^{-1}$.

Precipitation over the lake, the dominant source of water for Lake Victoria, is assumed to be a nonlinear function of the average rain gauge precipitation at six stations (Jinja, Entebbe, Kisumu, Musoma, Bukoba, and Mwanza) along the perimeter of the lake (Figure 1). Since station data is not readily available, CRU TS 3.21 gridded precipitation was used to investigate the modes of variability in Eastern Africa and their effects on Lake Victoria levels over the years 1950-2009. The CRU precipitation is interpolated to the six stations using WENO interpolation as described in [18]. The interpolated 


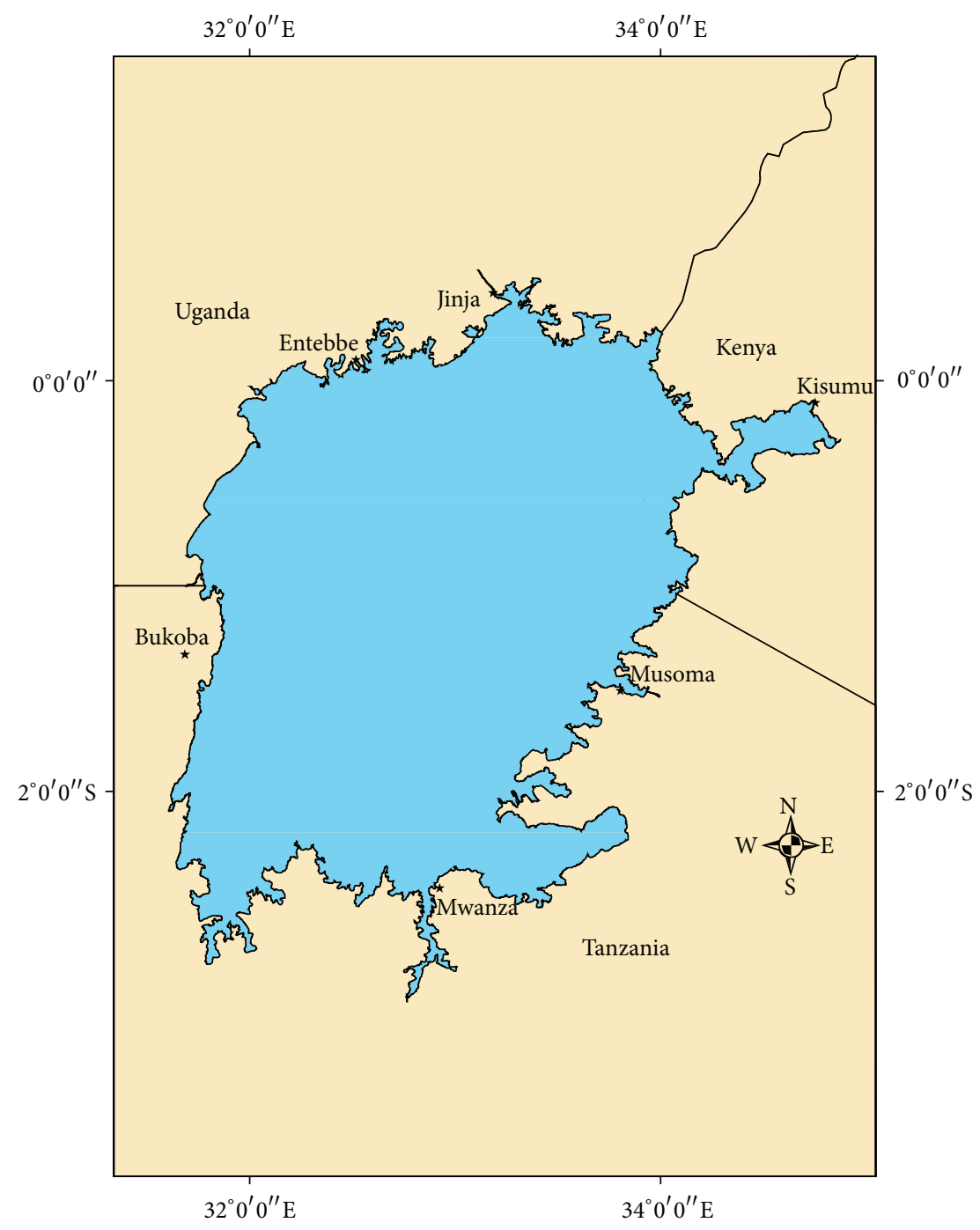

FIGURE 1: Location of stations used in water balance model.

station precipitation values are then used in place of the station gauge precipitation. The tributary inflow, $Q_{\mathrm{in}}$, is solved using the technique of [8], while $Q_{\text {out }}$ is found by solving the equation from [19]. Since $\Delta L_{n}$ appears on the left-hand side of the equation, and as part of the equation used to calculate $Q_{\text {out }}$, the equation must be solved iteratively. This procedure is executed using two iterations, setting $\Delta L_{n}=0$ on the first iteration.

Lake Victoria levels calculated using the water balance model are shown as a black line in Figure 2, while observed lake levels are shown in purple. The Lake Victoria level observations used in this study are based on a data set of lake level observations from January 1949 to May 1998 at a gauge at the main river outlet in Jinja, Uganda, obtained from an archive at the Ministry of Water Resources in Uganda [20]. This data set was extended through the present using TOPEX/POSEIDON and Jason-1 satellite altimetry data [21]. Since the heights obtained by satellite altimetry are an average of all topography within the instrument footprint further averaged in the direction of the satellite motion, these

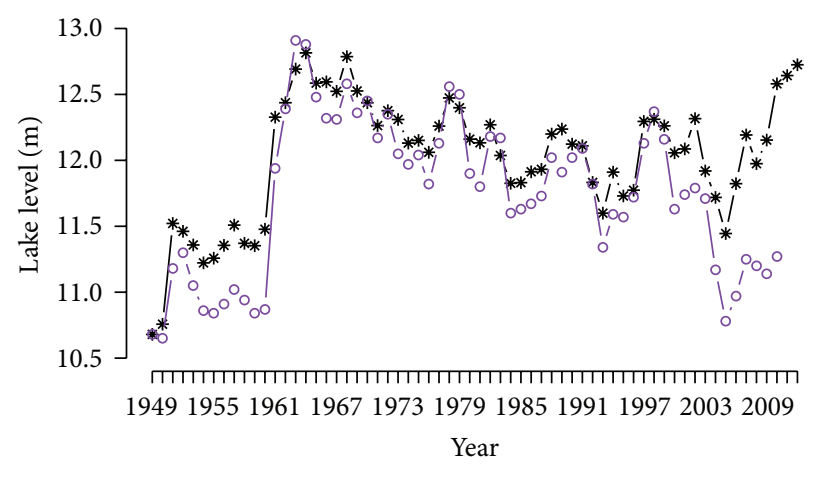

FIGURE 2: Comparison of Lake Victoria levels modeled using CRU 3.21 (black with asterisks) and observed lake levels (purple with circles).

values differ from traditional gauge measurements which are at specific points. Therefore, the TOPEX/POSEIDON and Jason-1 altimetry data is supplied as a lake height variation 
with respect to TOPEX/POSEIDON 10-year mean level. The climatological mean was found by subtracting the satellite data from the observations for the time period the two data sets had in common to determine the difference between the two. From this, a mean was found and added to the satellite anomalies. The mean was adjusted until bias and error were reduced to $-4 * 10^{-4}$ and 0.0585 , respectively [20]. The remaining satellite altimetry time series was then added to the resulting mean, creating a combined data set for January 1949 through the present. The first two years of the jump in levels from 1961 to 1964 are captured, while the modeled lake levels are slightly lower than observed in 1963-64. The model does well until the 1980s when it underpredicts lake levels by up to 0.5 meters in 1983 and then predicts higher than observed levels in the late 1990s through 2005, overpredicting by as much as $0.73 \mathrm{~m}$ in 2005 , which is most likely related to the overrelease from Nalubaale and Kiira dams found by Kull [11] and expanded upon in [12].

\section{Results}

3.1. Annual Rainfall. The first mode of annual variability accounts for 37.7 percent of variability. The loading (Figure 3(a)) is mostly positive with a time series showing a high amount of variability but a general drying trend after 1961 (Figure 3(b)). The second mode of annual precipitation variability, which accounts for 9 percent of variability, has a positive loading surrounding the lake and to the north into Uganda and Kenya, with a negative loading to the south (Figure 3(c)). The time series shows a decadal oscillation with the largest variation in the late 1970s and early 1980s (Figure 3(d)). The third mode of variability is also significant and accounts for just over 7 percent of the variability. The loading has a positive pattern to the north and south of the lake basin, with a negative loading to the east (Figure 3(e)). Over the lake, there is close to neutral negative loading (Figure 3(f)).

Lake levels calculated using precipitation reconstructed from individual significant modes of annual precipitation variability, compared to the level obtained using the total annual precipitation, are shown in Figure 4 . The precipitation reconstructed from the first significant mode of variability accounts for the majority of variability in Lake Victoria levels, while the effects of the second and third modes on the variability of lake levels are negligible. The increase in modeled levels from 1949 to 1963 using each of the filtered precipitation time series occurs as the model adjusts to the increase in average annual precipitation during that period.

3.2. Seasonal Variability. In order to understand the physical meaning behind the annual modes of variability, we examine the significant modes of variability for the short rains of October through December (OND) and the long rains of March through May (MAM). We relate these seasonal modes to the annual modes used above.

3.2.1. Short Rains (OND Season). The first three modes of variability for the short rains, OND season, are significant and account for just over $71 \%$ of the variability for this season. We will examine these modes in detail.

The first mode of OND station precipitation variability has a loading which is entirely positive (Figure 5(a)). The time series we obtain for the first mode of variability of OND station precipitation reproduces the time series found by [3] for 1961-90. This first mode explains $57.4 \%$ of the variability. Schreck III and Semazzi [3] related their EOF1 to ENSO by correlating their time series with the first significant EOF mode from global CMAP precipitation. They found that the first mode from the EOF analysis on regional precipitation corresponds to a combination of the first global EOF mode representing ENSO and the second global mode representing IOZM. The major warm ENSO events for the period correspond to the high peaks of the time series. In particular, the ENSO of 1982 is distinctly conspicuous. When the first mode from OND precipitation is correlated with SSTs for 1950-2012, an ENSO pattern emerges (Figure 6). IOZM often occurs simultaneously with ENSO; however, the difference between the IO ZM positive and negative years without ENSO for this mode is not statistically significant. This mode has a high correlation (0.77) with the first annual mode. Therefore, the first mode of OND variability and the first annual mode are considered to be ENSO.

Similar to [3], the second mode of variability for station precipitation is significant. The second mode is a dipole mode with negative loading to the north and positive loading to the south, which split the stations used in the water balance model; the stations to the north of the lake are in an area of negative loading, while those on the southern coast of the lake are in a region with a positive loading (Figure 5(c)). The corresponding time series exhibits both strong interannual variability and low-frequency background variability (Figure 5(d)). Overall, there is an increasing trend in the time series of the second mode from 1949 through 1986, followed by a decreasing trend until 1997, which is then followed by another increasing trend. Interpretation of the distribution of loadings and the corresponding time series suggests that the southern sector of Eastern Africa became wetter during the period from 1961 to 1990 , while the northern section has been drying up during the same time period. This is opposite to the dipole described by [3] who claim that the northern sector has been getting wetter while the southern sector has been drying up. While our time series is similar to the time series in [3] over 1961-90, our loadings are the inverse of theirs. We find that their Gauge-EOF2 loading must have been inverted. There is no clear signal when this mode of variability is correlated with global SSTs. This mode has a -0.40 correlation with the second annual mode, which suggests that it might be related to the second annual mode. It has a higher, 0.44 correlation with the third annual mode.

The third mode of OND variability is also shown to be statistically significant, accounting for 4.1 percent of variability over the region during the OND season. The loading for this mode shows an East-West dipole, with a positive loading to the west and a negative loading to the east, which is near neutral over Lake Victoria but has sharp contrasts over Kenya (Figure 5(e)); the time series shows high peaks in 1961, 1962, 1999, and 2012, while there are sharp dips in 1967, 1968, 1986, 


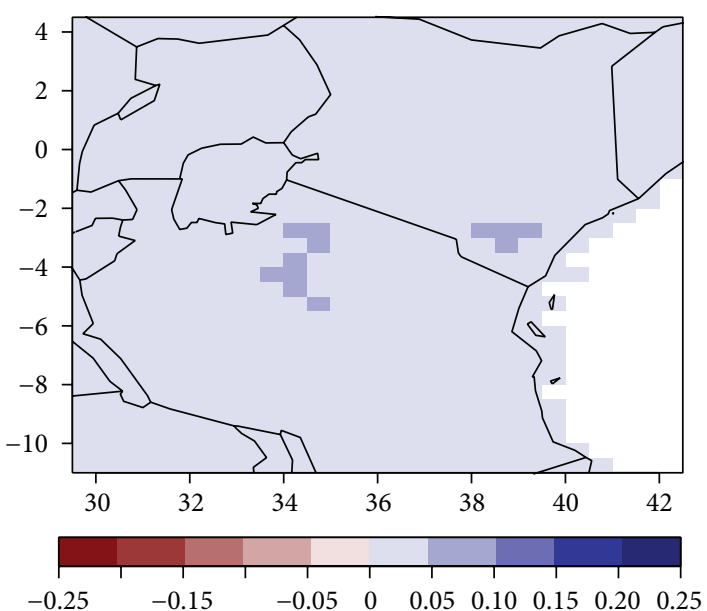

(a)

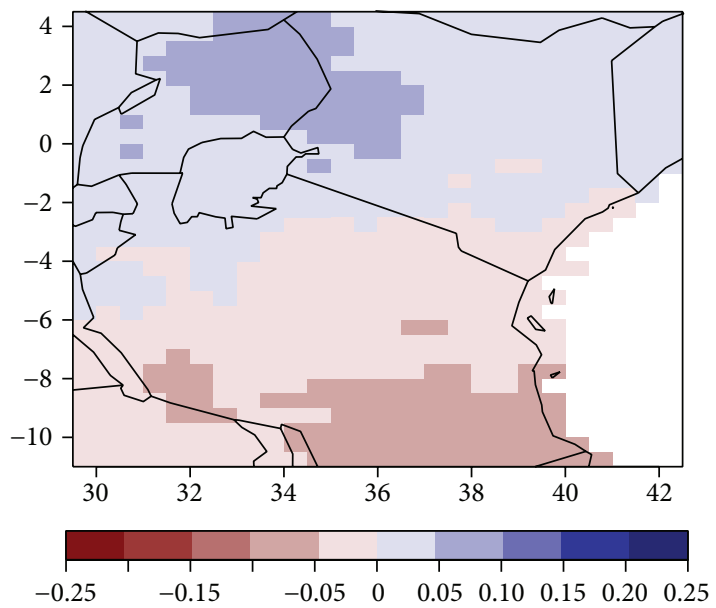

(c)

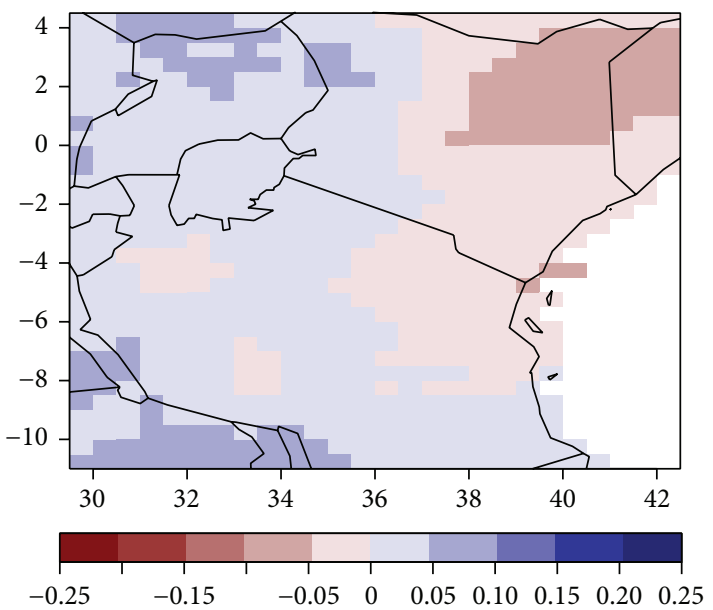

(e)

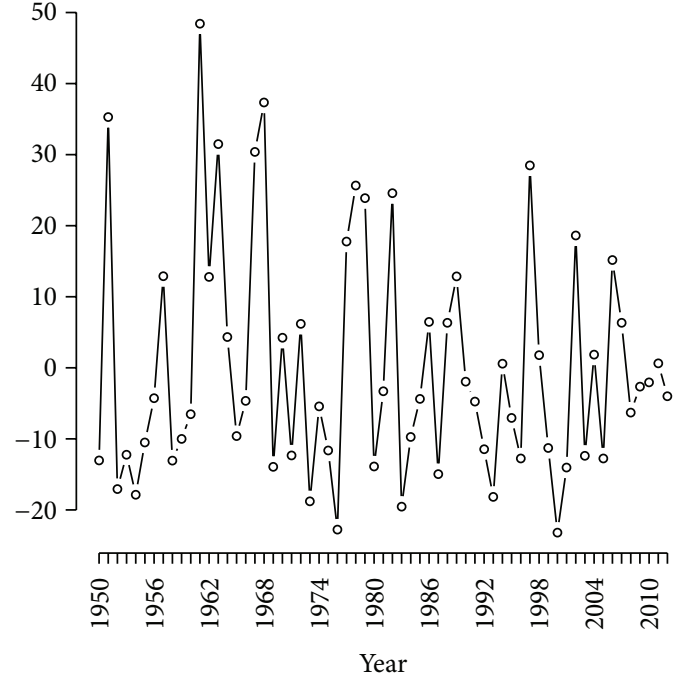

(b)

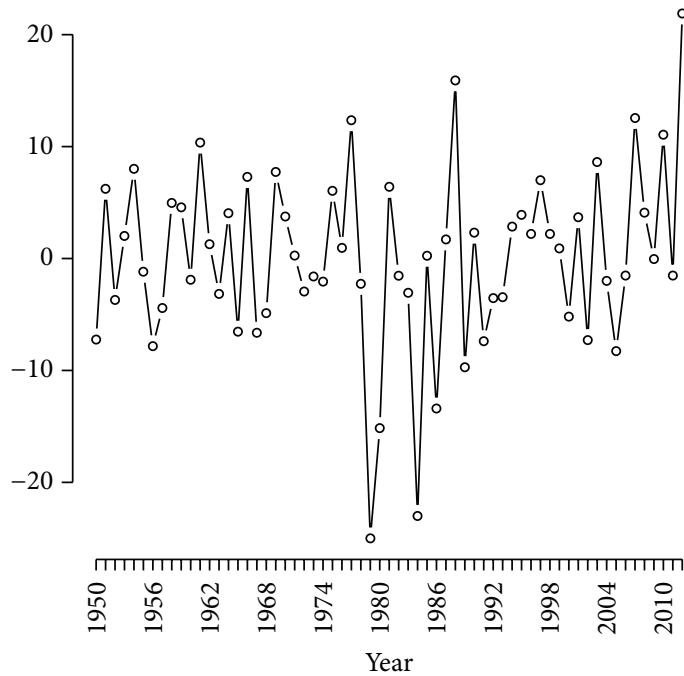

(d)

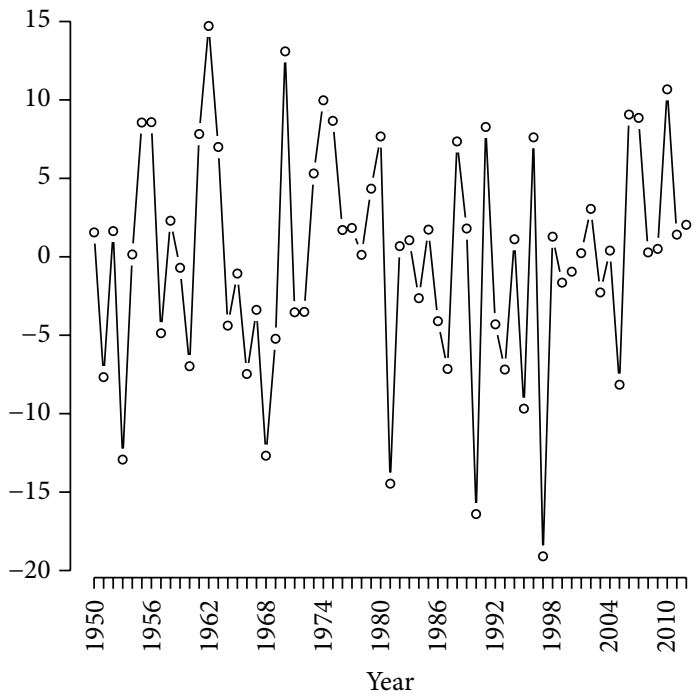

(f)

FIGURE 3: EOF loadings and time series for first ((a), (b)), second ((c), (d)), and third ((e), (f)) modes of variability for annual precipitation. 


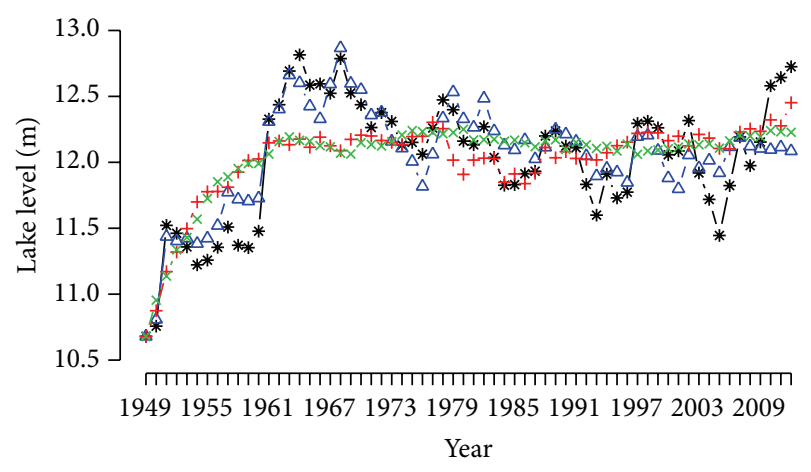

FIGURE 4: Results of using individual modes of annual precipitation variability in the water balance model for Lake Victoria. Levels modeled using the unfiltered CRU 3.21 dataset are in black (asterisks); levels modeled using precipitation accounted for by the first mode of annual variability are in blue (triangles); levels modeled using precipitation accounted for by the second mode of variability are in red (crosses), while levels modeled using precipitation accounted for by the third mode of variability are in green ( $x$ 's).

and 1997 (Figure 5(f)). This mode is correlated with SSTs in the Pacific Ocean, off the coast of Mexico (Figure 7). It has a 0.32 correlation with the second mode of annual rainfall variability.

3.2.2. Long Rains (MAM Season). The first four modes of variability for the long rains, MAM season, are significant and account for just over $51 \%$ of the variability for this season. We will examine these modes in detail.

Approximately 42 percent of the total East African rainfall is observed during the MAM season [4]. In the MAM season, there are four significant modes of variability for CRU TS 3.21 precipitation. The first significant mode accounts for $27.5 \%$ of the variability for station precipitation. The loading (Figure $8(\mathrm{a})$ ) is mostly negative over the lake basin and has a -0.58 correlation with the first mode of annual variability. The corresponding time series (Figure 8(b)) shows an increasing trend with less variability in recent years. We investigate the source of variability for the mode by correlating it with SST and find a positive correlation with SSTs off the coast of Africa, between South Africa and Madagascar (Figure 9). This mode is examined in more detail since it accounts for a large amount of variability during the MAM season and has a decreasing trend in rainfall similar to that found in [22]. The decrease in trend in our study starts earlier than the abrupt change found in [22]. They relate the decreasing rainfall during this season starting around 1980 to SST anomalies in the Pacific. The difference between positive and negative composites of the time series for this mode with SST anomalies and $850 \mathrm{mb}$ wind anomalies shows an ENSO-like signal similar to [23] (Figure 10); however, the mode is not significantly correlated with ENSO. Song and Zhang [23] attribute the El Niño-like SST warming to cloud feedback, further amplified by water vapor feedback. The corresponding wind anomalies over Eastern and near equatorial Africa (Figure 10) are consistent with Gill-type solution [24]. We believe that this is associated with the trend of reduced midtropospheric diabatic heating associated with the reduced rainfall over the region.

The second mode is significant and has a -0.64 correlation with the second mode of annual variability. It accounts for $10.2 \%$ of variability in rainfall during the MAM season. The mode is split over Lake Victoria with slightly positive loadings near the northern and western shore and slightly negative loadings over the rest of the lake with stronger positive loadings to the south of the region (Figure 8(c)). There are no clear signals when this mode is correlated with global SSTs. The time series for this mode (Figure 8(d)) is not correlated with the time series of second mode of OND precipitation even though their loadings appear similar. More work needs to be done to identify the physical mechanism for this mode, although it may be related to the north-south movement of the Intertropical Convergence Zone (ITCZ) as it passes over this region during the long rain season.

The third mode, accounting for $8.6 \%$ of the variability, has a 0.53 correlation with the third mode of annual variability. This mode has a slightly negative loading in the northwest corner of Lake Victoria but a slightly positive loading over the remainder of the lake. The strongest negative loadings are near the coast, while the strongest positive loadings are in northern Uganda (Figure 8(e)). There are no clear signals when time series for this mode (Figure $8(\mathrm{f})$ ) is correlated with global SSTs. This mode may be related to moisture convergence from the Indian Ocean; however, more work is needed to identify the physical mechanism.

The fourth mode of variability for the MAM season is also significant; however, it is not correlated with any of the significant modes of annual precipitation used in the water balance model for Lake Victoria. Due to this lack of correlation, the fourth mode of MAM precipitation variability is not analyzed in this study.

\section{Conclusions}

We find that the first EOF mode of annual precipitation variability, ENSO, has the highest impact on the annual variability of Lake Victoria level. It has high correlation with the first modes of variability during the short rain (OND) and long rain (MAM) seasons. The first mode of variability during the OND season is found to be a combination of ENSO, while more work needs to be done to determine the physical mechanism behind the first mode of variability during the MAM season, although it is positively correlated with SSTs near Madagascar, suggesting that it is related to the moisture flux in that region.

While the second EOF mode of annual variability accounts for approximately 10 percent of the variability, its effect on the variability in lake levels is negligible. The second EOF mode of annual precipitation variability is significantly correlated with the second and third EOF modes of variability from the OND season and the second mode from the MAM seasons. Based on the EOF analysis of OND season rainfall, the dipoles in the second and third modes are split with very small values over the lake. The dipole in the MAM season also has small loadings over the lake. This suggests that the dipole may have negligible effect on Lake Victoria levels due to the 


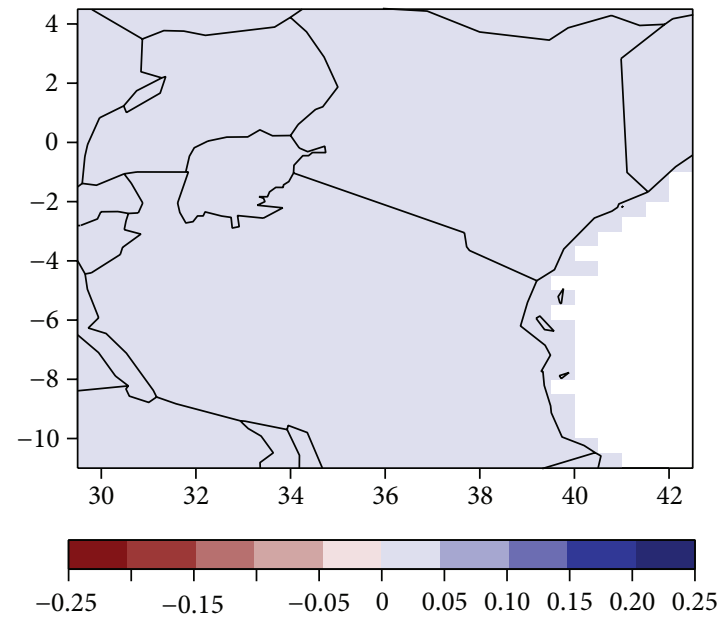

(a)

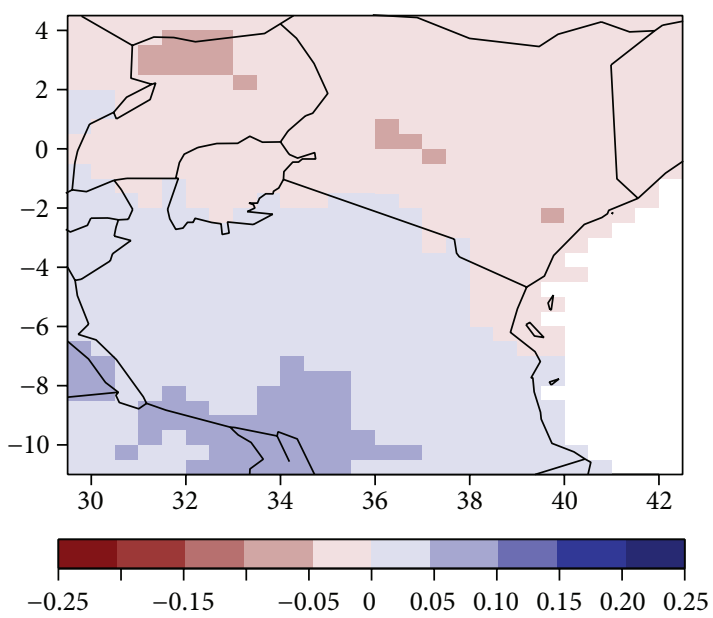

(c)

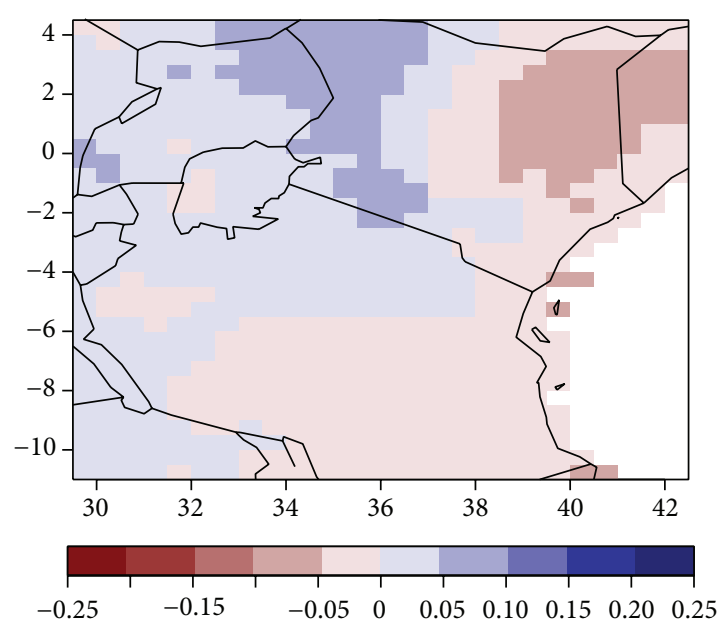

(e)

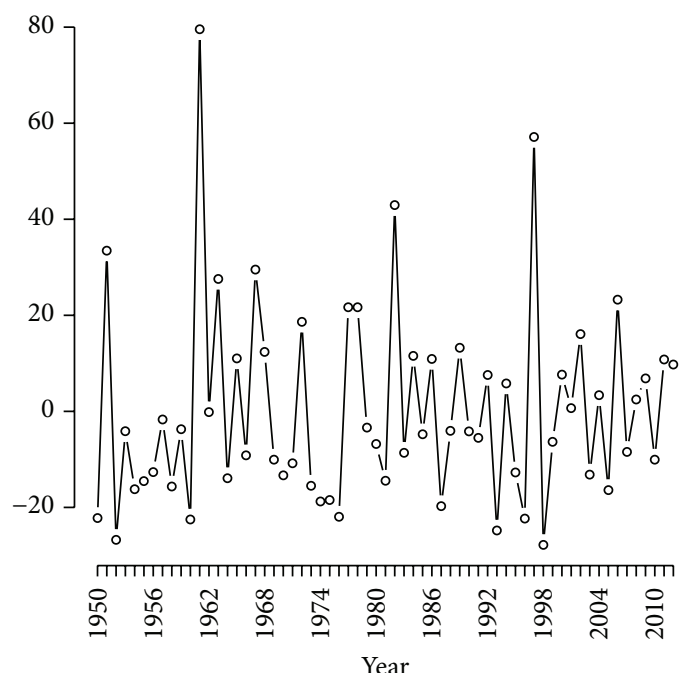

(b)

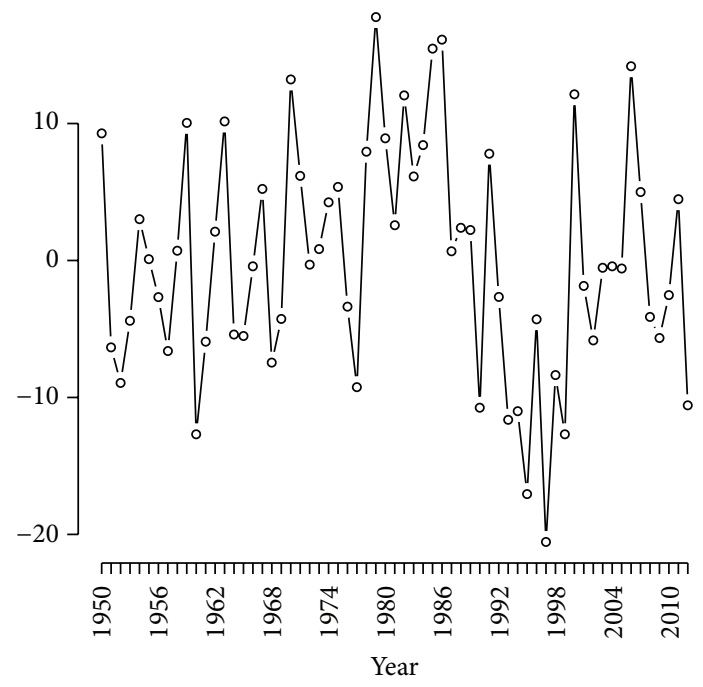

(d)

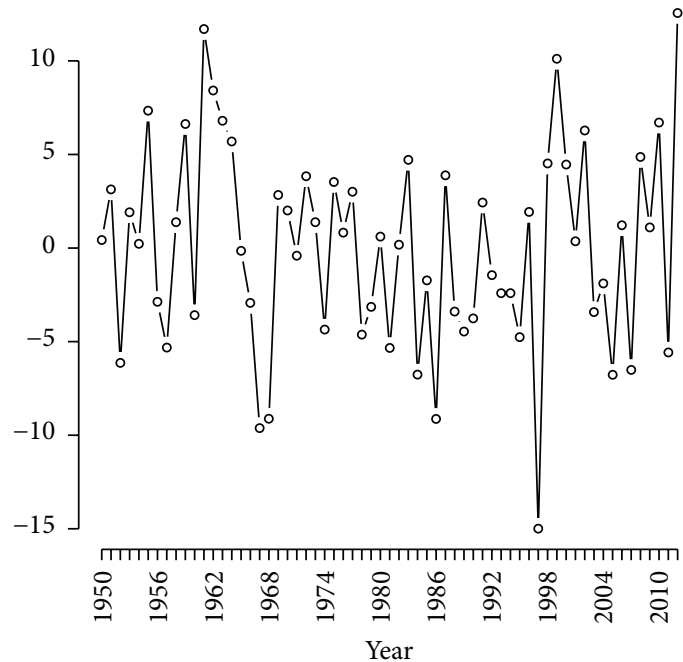

(f)

FIGURE 5: Same as Figure 3, but for short rains (OND) precipitation. 
TABLE 1: Regressions of rainfall for 1956-1990. $P_{c}$ is catchment rainfall; $P_{l}$ is lake rainfall (from Tate).

\begin{tabular}{lcr}
\hline Catchment & Regression & Correlation, $R^{2}$ \\
\hline Nzoia & $P_{c}=\left(0.685 * P_{l}\right)+154.5$ & 0.54 \\
Yala & $P_{c}=\left(0.951 * P_{l}\right)+64.7$ & 0.61 \\
Sondu & $P_{c}=\left(0.666 * P_{l}\right)+302.6$ & 0.39 \\
Awach Kaboun & $P_{c}=\left(0.785 * P_{l}\right)+337.4$ & 0.28 \\
Kagera & $P_{c}=\left(0.556 * P_{l}\right)+142.8$ & 0.60 \\
\hline
\end{tabular}

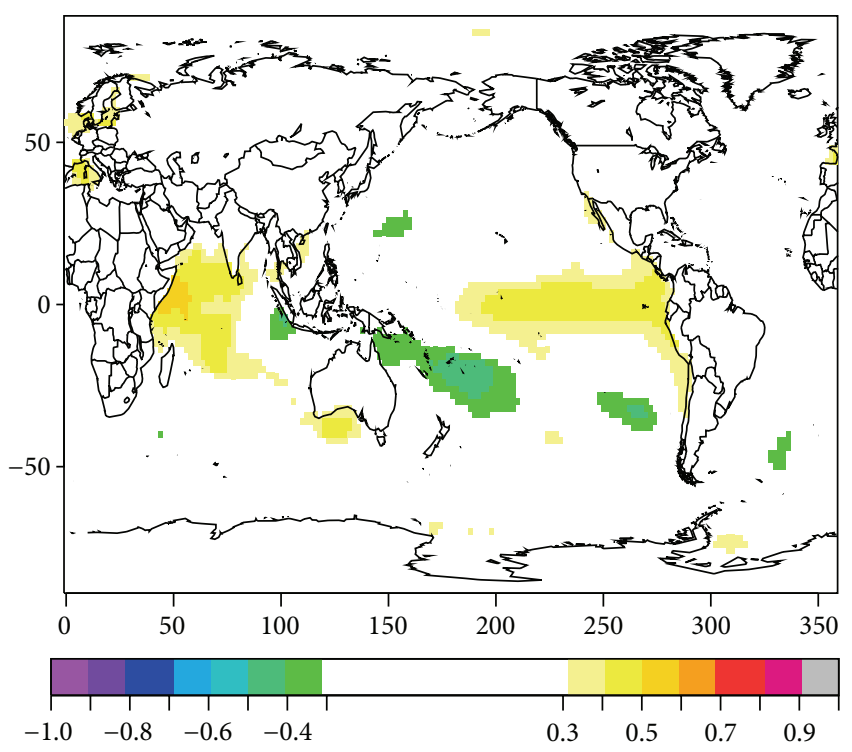

FIgure 6: Pearson Correlation of the time series for the first mode of OND season precipitation variability with ERSST sea surface temperatures.

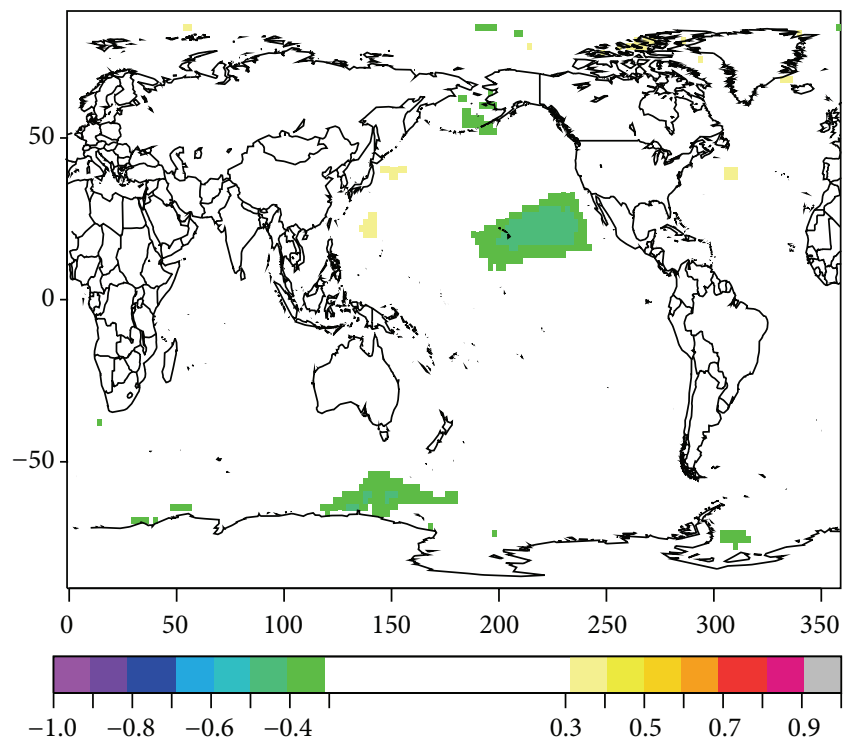

FIgURE 7: Pearson Correlation of the time series for the third mode of OND season precipitation variability with ERSST sea surface temperatures. fact that the loadings for the annual dipole are overall small since, in the OND and MAM seasons, there is a combination of positive and negative loadings over the lake that almost completely cancels out once the rainfall is interpolated to the six stations and used as input in the water balance model.

The third EOF mode of annual variability accounts for slightly over 7 percent of the variability over East Africa. It is correlated with the second mode of OND rainfall variability and the third mode of MAM variability. Similar to the second annual mode, it has negligible impact on the levels of Lake Victoria, most likely because the dipole modes over the lake are relatively small and may be cancelling each other out when they are combined.

We have sought to estimate the relative contributions of the dominant modes of annual precipitation variability to the modulation of Lake Victoria levels for the present day (1950-2012). The modes found in this study should be used to evaluate climate models over this region. Climate projections should be evaluated to investigate the evolution of these modes in the future. A change in ENSO, or a shift in one of the other modes described in this study, could have a great impact on the levels of Lake Victoria in the future.

\section{Appendix}

\section{Calculation of $Q_{\text {in }}$ and $Q_{\text {out }}$ in Water Balance Model}

Inflow, $Q_{\text {in }}$, is calculated as a nonlinear function with precipitation, $P$, as the input. Subcatchment rainfall $\left(P_{c}\right)$ is estimated for each of five tributaries (Nzoia, Yala, Sondu, Awach Kaboun, and Kagera) using regressions of annual total data for the period 1965-1990 (Table 1). The runoff coefficient for each catchment is then estimated from the subcatchment rainfall by linear regression derived by [25] as

$$
r_{c}=0.0002 P_{c}-0.1386
$$

The runoff from each subcatchment to Lake Victoria is then estimated by multiplying each subcatchment's rainfall by the runoff coefficient and the subcatchment area. The total inflow to Lake Victoria, $Q_{\text {in }}$, is estimated as the runoff of Nzoia, Yala, Sonduuu, and Awach Kaboun scaled up by a factor of 2.7 on an annual basis, plus the flow of the Kagera increased by $10 \%$ to account for the flow of the Ngono tributary, which joins it downstream of the gauging station [8]. 


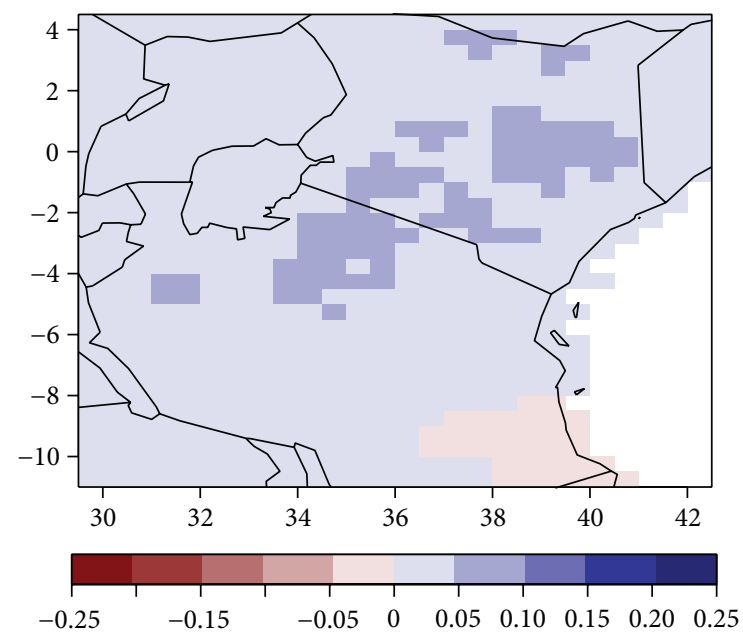

(a)

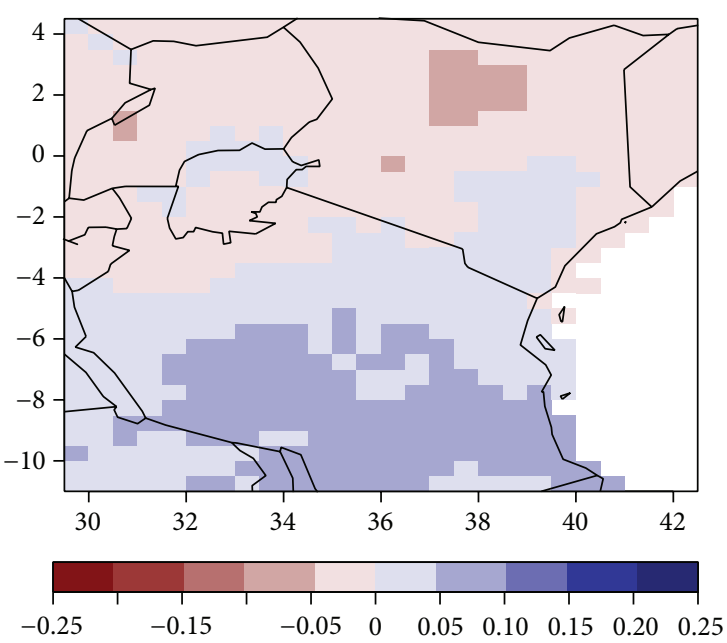

(c)

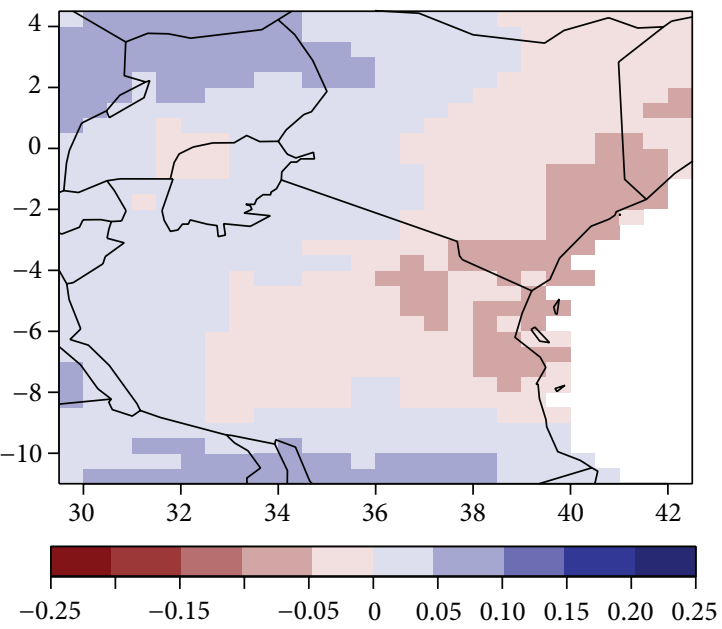

(e)

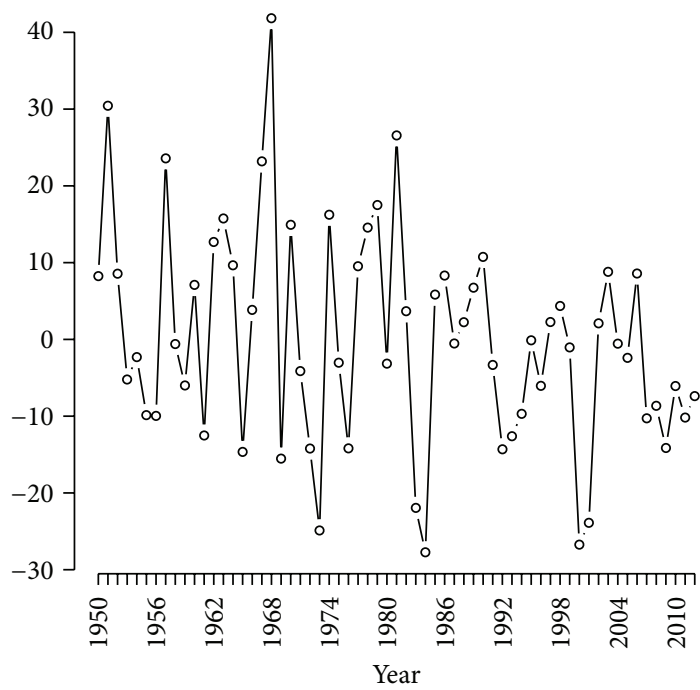

(b)

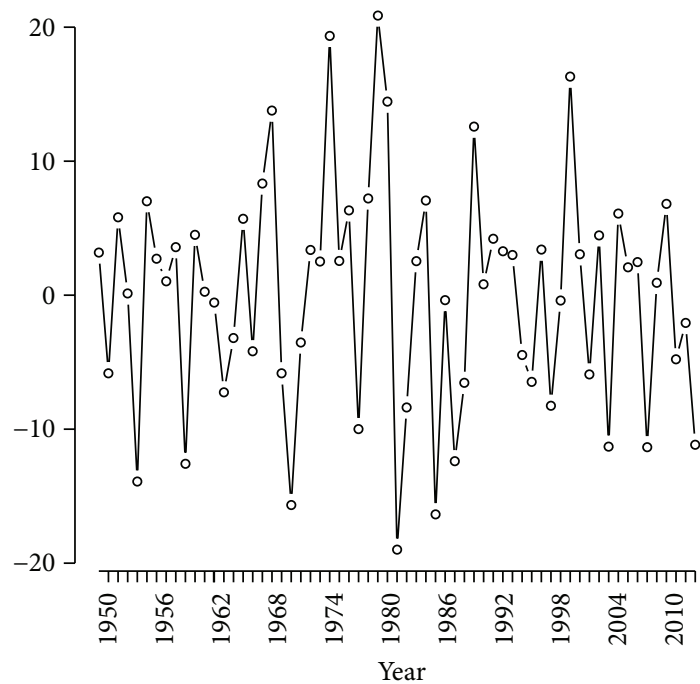

(d)

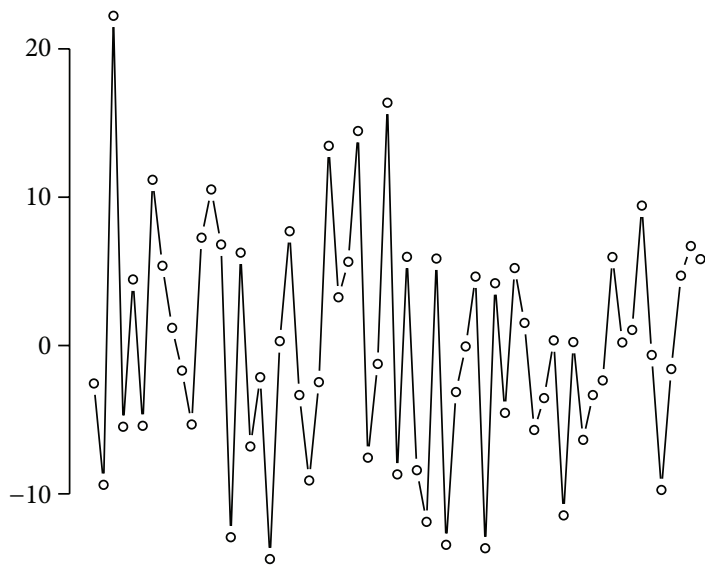

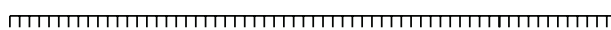

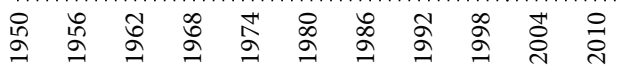
Year

(f)

FIGURE 8: Same as Figure 3, but for long rains (MAM) precipitation. 


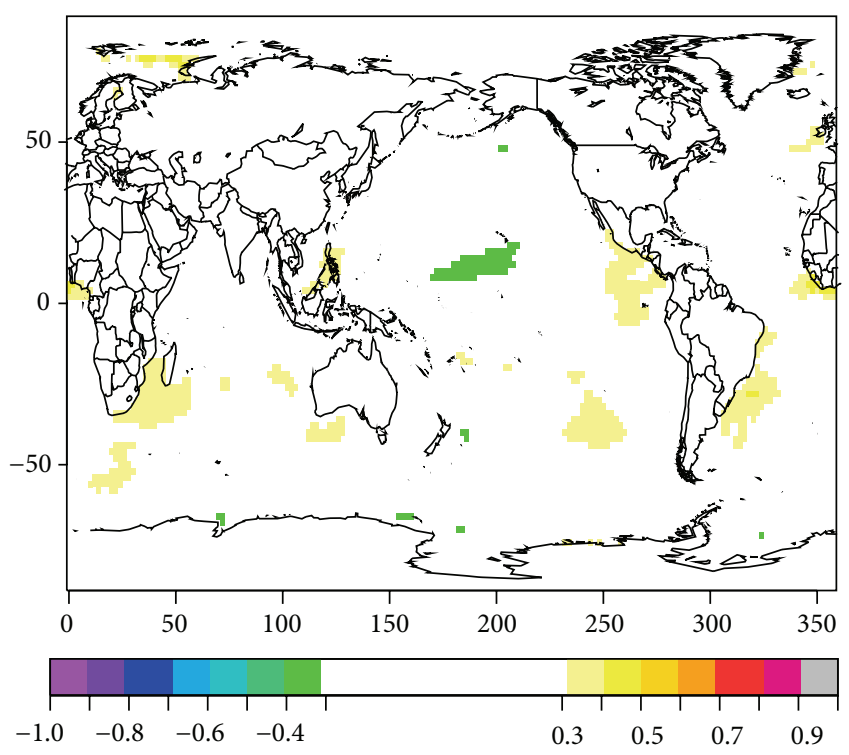

FIgURE 9: Pearson Correlation of the time series for the first mode of MAM season precipitation variability with ERSST sea surface temperatures.

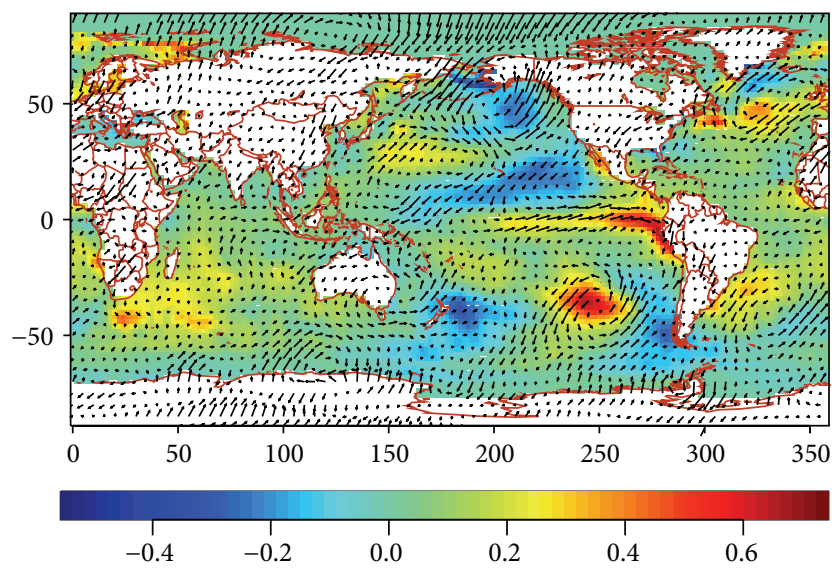

FIGURE 10: Difference between positive and negative composites of MAM EOF1 with SSTs and $850 \mathrm{mb}$ winds.

The outflow, $Q_{\text {out }}$, is calculated from the Agreed Curve based on the current lake level. We use the estimation of the Agreed Curve from [19]

$$
Q_{\text {out }}=66.3\left(L_{n}-7.96\right)^{2.01} \text {, }
$$

where $L_{n}$ is the current Lake Victoria level. Since $L_{n}$ is initially unknown, and as part of the equation to calculate $Q_{\text {out }}$, the water balance model is initially solved setting $L_{n}$ to the previous year's level to calculate an estimated $L_{n}$; the estimated $L_{n}$ is then used to calculate the outflow in a second iteration of the model for each year.

\section{Conflict of Interests}

The authors declare that there is no conflict of interests regarding the publication of this paper.

\section{Acknowledgments}

The authors wish to thank Dr. Emma (Tate) Brown for her assistance with the water balance model. This research was supported by NSF Grant AGS-1043125 and NSF Expeditions in Computing Award no. 1029711.

\section{References}

[1] R. O. Anyah and F. H. M. Semazzi, "Climate variability over the Greater Horn of Africa based on NCAR AGCM ensemble," Theoretical and Applied Climatology, vol. 86, no. 1-4, pp. 39-62, 2006.

[2] J. H. Bowden and F. H. M. Semazzi, "Empirical analysis of intraseasonal climate variability over the Greater Horn of Africa," Journal of Climate, vol. 20, no. 23, pp. 5715-5731, 2007.

[3] C. J. Schreck III and F. H. M. Semazzi, "Variability of the recent climate of eastern Africa," International Journal of Climatology, vol. 24, no. 6, pp. 681-701, 2004.

[4] M. Indeje, F. H. M. Semazzi, and L. J. Ogallo, "ENSO signals in East African rainfall seasons," International Journal of Climatology, vol. 20, no. 1, pp. 19-46, 2000.

[5] G. W. Kite, "Recent changes in level of Lake Victoria," Hydrological Sciences Bulletin, vol. 26, no. 3, pp. 233-243, 1981.

[6] B. S. Piper, D. T. Plinston, and J. V. Sutcliffe, “The water balance of Lake Victoria," Hydrological Sciences Journal, vol. 31, no. 1, pp. 25-37, 1986.

[7] K. J. Sene and D. T. Plinston, "A review and update of the hydrology of Lake Victoria in East Africa," Hydrological Sciences Journal, vol. 39, no. 1, pp. 47-63, 1994.

[8] E. Tate, J. Sutcliffe, D. Conway, and F. Farquharson, "Water balance of Lake Victoria: update to 2000 and climate change modelling to 2100," Hydrological Sciences Journal, vol. 49, no. 4, pp. 563-574, 2004.

[9] X. Yin and S. E. Nicholson, "Interpreting annual rainfall from the levels of Lake Victoria," Journal of Hydrometeorology, vol. 3, no. 4, pp. 406-416, 2002.

[10] J. V. Sutcliffe and G. Petersen, "Lake Victoria: derivation of a corrected natural water level series," Hydrological Sciences Journal, vol. 52, no. 6, pp. 1316-1321, 2007.

[11] D. Kull, Connections between Recent Water Level Drops in Lake Victoria, Dam Operations and Drought, 2006, http://www.internationalrivers.org/files/attached-files/full_report_pdf.pdf.

[12] D. Kull, "Addendum to: connections between recent water level drops in Lake Victoria, dam operations and drought," 2006, http://www.internationalrivers.org/resources/addendum-lakevictoria-report-4118.

[13] I. Harris, P. D. Jones, T. J. Osborn, and D. H. Lister, "Updated high-resolution grids of monthly climatic observations-the CRU TS3.10 Dataset," International Journal of Climatology, vol. 34, no. 3, pp. 623-642, 2013.

[14] C. S. Breetherton, C. Smith, and J. M. Wallace, "An intercomparison of methods of finding coupled patterns in climate data," Journal of Climatology, vol. 5, pp. 541-560, 1992.

[15] M. Kendall, Multivariate Analysis, Hodder, Arnold, New York, NY, USA, 2nd edition, 1980.

[16] K. M. Weickmann and R. M. Chervin, "The observed and simulated atmospheric seasonal cycle. Part I: global wind field modes," Journal of Climate, vol. 1, no. 3, pp. 265-289, 1988. 
[17] F. H. M. Semazzi, B. Burns, N.-H. Lin, and J.-K. Schemm, "A GCM study of the teleconnections between the continental climate of Africa and global sea surface temperature anomalies," Journal of Climate, vol. 9, no. 10, pp. 2480-2497, 1996.

[18] G. Capdeville, "A Hermite upwind WENO scheme for solving hyperbolic conservation laws," Journal of Computational Physics, vol. 227, no. 4, pp. 2430-2454, 2008.

[19] K. J. Sene, "Theoretical estimates for the influence of Lake Victoria on flows in the upper White Nile," Hydrological Sciences Journal, vol. 45, no. 1, pp. 125-145, 2000.

[20] N. N. Davis, Dynamic and stochastic modeling of various components of the hydrological cycle for East Africa [M.S. thesis], North Carolina State University, 2007.

[21] USDA, "Radar altimeter data from NASA/CNES Topex /Poseidon and Jason-1 satellite missions. Time series of altimetric lake level variations from the USDA Reservoir Database," 2012, http://www.pecad.fas.usda.gov/cropexplorer/global_reservoir.

[22] B. Lyon and D. G. Dewitt, "A recent and abrupt decline in the East African long rains," Geophysical Research Letters, vol. 39, no. 2, Article ID L02702, 2012.

[23] X. Song and G. Zhang, "Role of climate feedback in El Niño-like SST response to global warming," Journal of Climate, 2014.

[24] A. E. Gill, "Some simple solutions for heat-induced tropical circulation," Quarterly Journal, vol. 106, no. 449, pp. 447-462, 1980.

[25] J. V. Sutcliffe and Y. P. Parks, "The hydrology of the nile," IAHS Special Publication 5, IAHS Press, Institute of Hydrology, Wallingford, UK, 1999. 

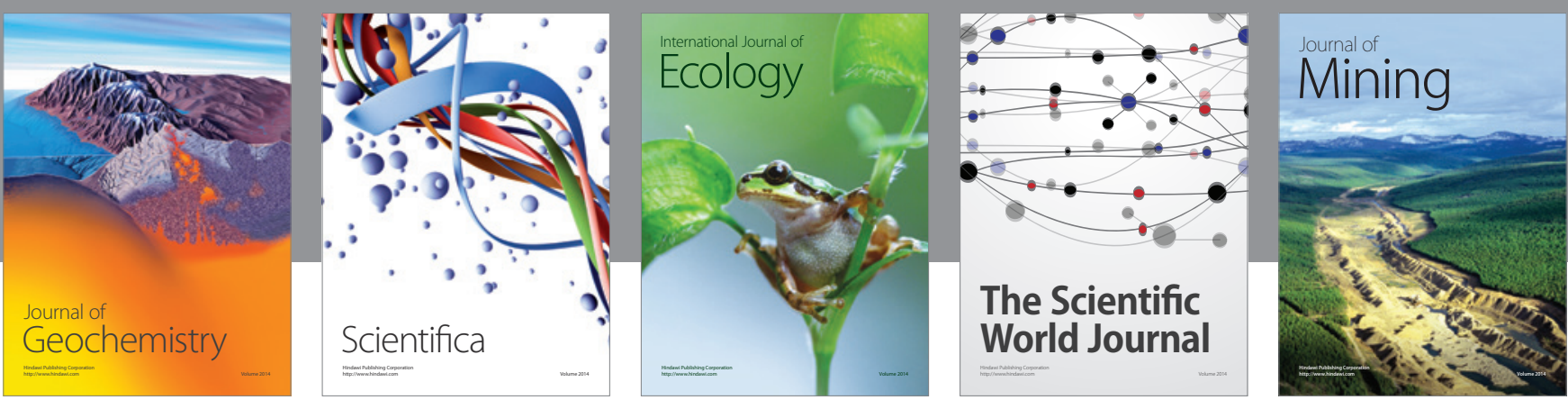

The Scientific World Journal
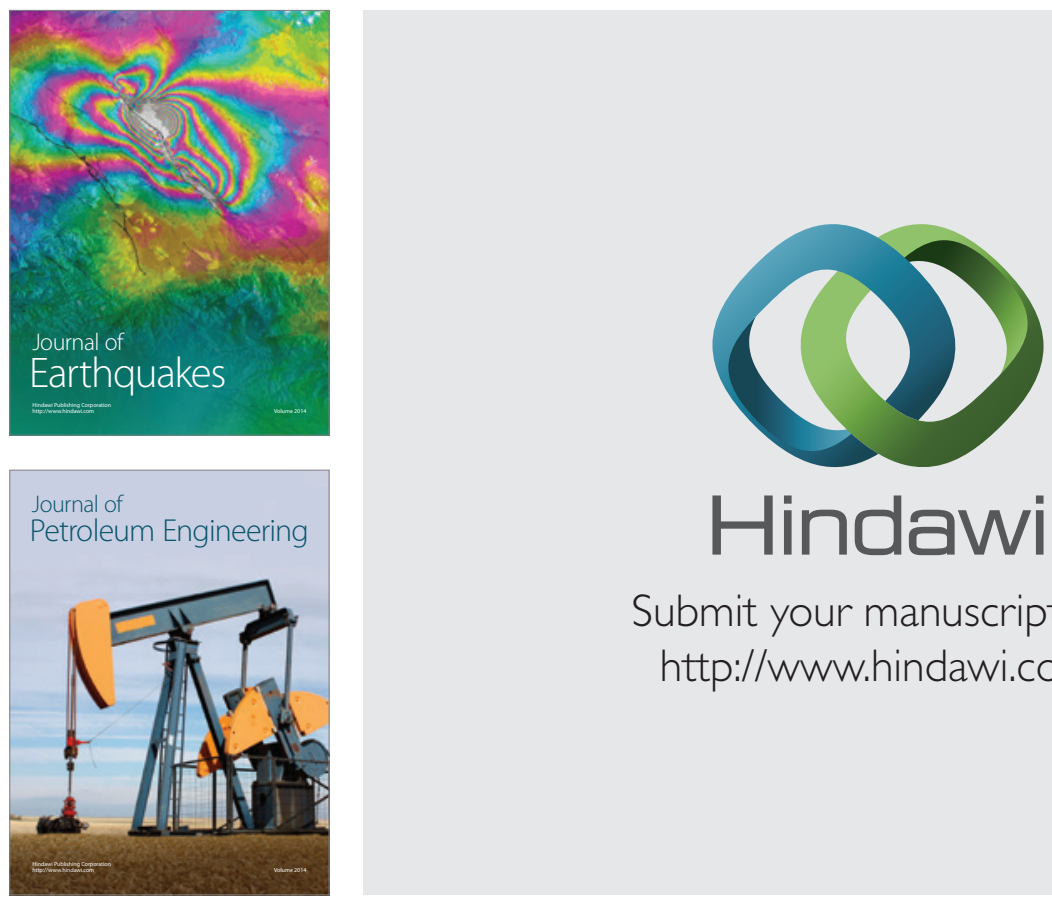

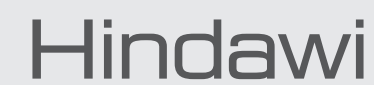

Submit your manuscripts at

http://www.hindawi.com
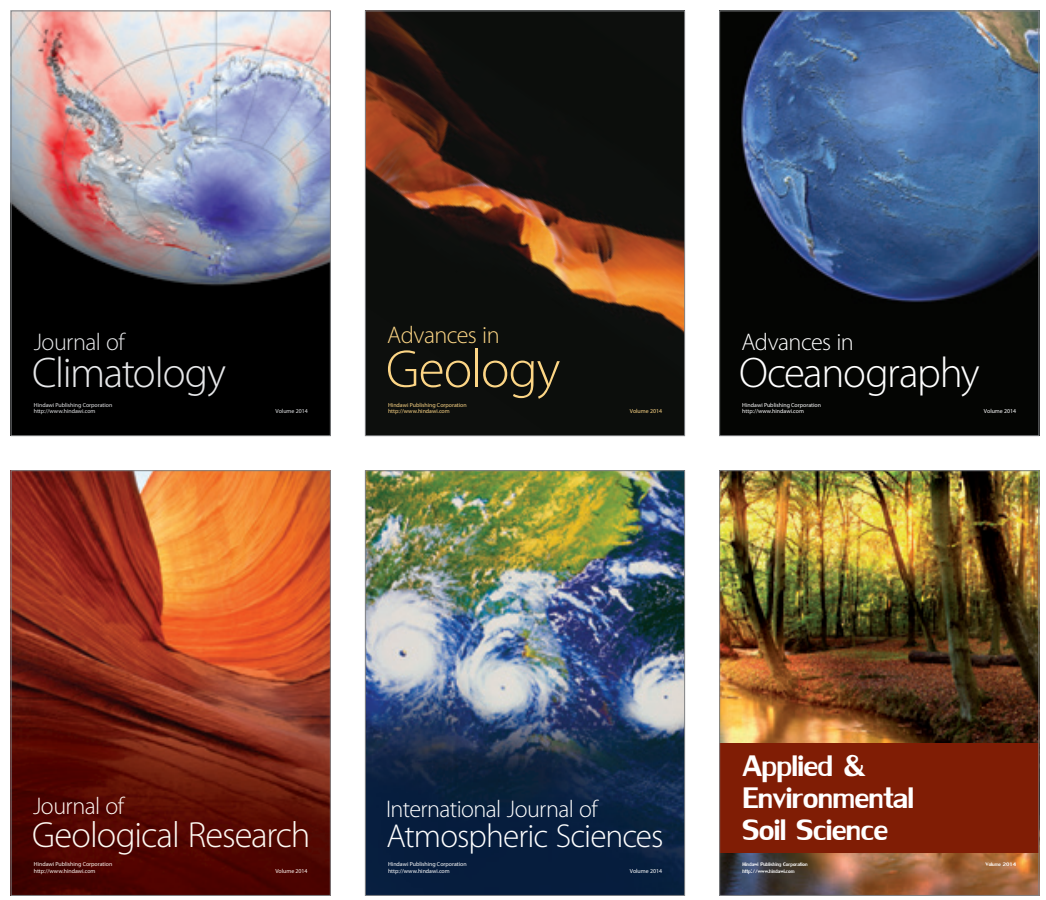
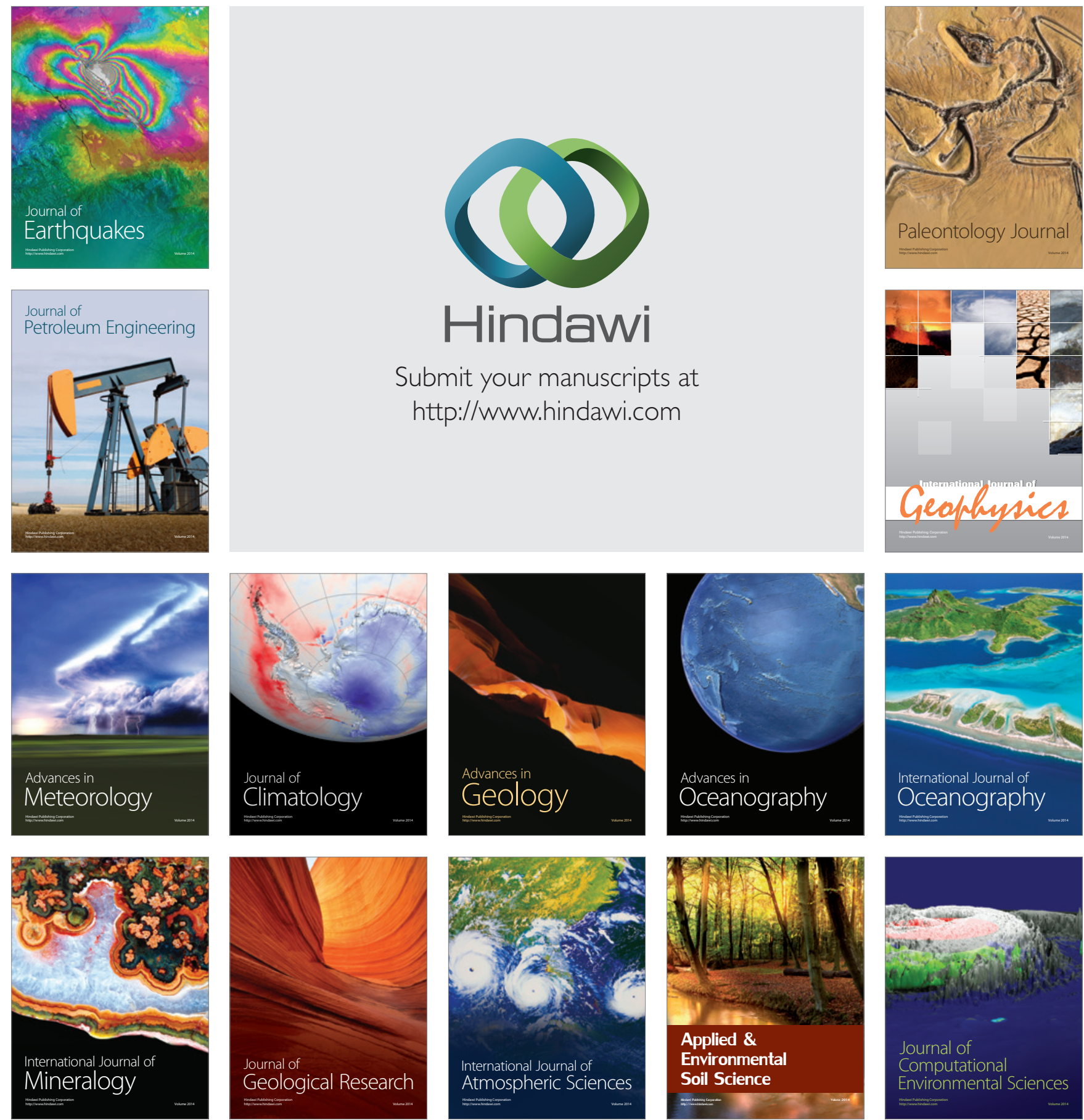